\title{
Effect of Community-Level Intervention on Early Initiation and Optimal Antenatal Care Attendance: A Quasi-Experimental Study Among Post-Partum Women in Eastern Uganda
}

Solomon T Wafula ( $\nabla$ swafula@musph.ac.ug )

Makerere University

Aisha Nalugya

Makerere University

Rornald M Kananura

Makerere University

Richard K Mugambe

Makerere University

Moses Kyangwa

Makerere University

John B Isunju

Makerere University

Betty Kyobe

Makerere University

Tonny Ssekamatte

Makerere University

Sarah Namutamba

Makerere University

Gertrude Namazzi

Makerere University

Elizabeth K Ekirapa

Makerere University

David Musoke

Makerere University

Florian Walter

The University of Manchester

Peter Waiswa

Makerere University 


\section{Research Article}

Keywords: Community health workers, Optimal antenatal care, Early initiation, Eastern Uganda

Posted Date: July 29th, 2021

DOI: https://doi.org/10.21203/rs.3.rs-711304/v1

License: (c) (i) This work is licensed under a Creative Commons Attribution 4.0 International License. Read Full License 
Effect of Community-level intervention on early initiation and optimal antenatal care attendance: A quasi-experimental study among post-partum women in Eastern Uganda

\section{Authors:}

Solomon T Wafula ${ }^{1,2^{*}}$, Aisha Nalugya ${ }^{1}$, Rornald M Kananura ${ }^{3}$, Richard K Mugambe ${ }^{1}$, Moses Kyangwa $^{3}$, John B Isunju ${ }^{1}$, Betty Kyobe ${ }^{3}$, Tonny Ssekamatte ${ }^{1}$, Sarah Namutamba $^{3}$, Gertrude Namazzi $^{3}$, Elizabeth K Ekirapa ${ }^{3}$, David Musoke ${ }^{1}$, Florian Walter ${ }^{2}$, Peter Waiswa ${ }^{3,4}$

\section{Institutional affiliations}

1. Department of Disease Control and Environmental Health, School of Public Health, College of Health Sciences, Makerere University, Kampala, Uganda

2. School of Health Sciences, Faculty of Biology, Medicine and Health, The University of Manchester, Manchester, United Kingdom

3. Department of Health Policy, planning and Management, School of Public Health, College of Health Sciences, Makerere University, Kampala, Uganda

4. Global Health Department of Public Health Sciences, Karolinska Institutet, Stockholm, Sweden

\section{Email addresses of authors}

Solomon TWafula: swafula@musph.ac.ug

Aisha Nalugya: aishanalugya18@gmail.com

Rornald M Kananura: mk.rornald@musph.ac.ug

Richard Mugambe : rmugambe@musph.ac.ug

Kyangwa moses :kyangwamoses@gmail.com

John B Isunju: isunju@musph.ac.ug

Betty Kyobe :bettykyobe@gmail.com

Tonny Ssekamatte : tssekamatte@musph.ac.ug

Sarah Namutamba :sarah.namutamba@gmail.com

Gertrude Namazzi : namazzi_ge@yahoo.co.uk

Elizabeth K Ekirapa : ekky@musph.ac.ug

David Musoke : dmusoke@musph.ac.ug

Florian Walter : florian.walter@manchester.ac.uk

Peter Waiswa : pwaiswa@musph.ac.ug

\section{Corresponding Author}

Solomon Tsebeni Wafula.

Email: swafula@musph.ac.ug; Tel +256775394293 


\begin{abstract}
Background: Initiating antenatal care within the first trimester and making at least four visits during pregnancy are recommended to enable screening and support for healthy lifestyles, well-being, and self-care in pregnancy. Due to glaring evidence on inequalities in access to antenatal care, this study assessed the effect of engaging community health structures on utilization of antenatal care services during pregnancy in resource-constrained rural settings in Uganda.
\end{abstract}

Methods: A quasi-experimental evaluation study was conducted among mothers in Eastern Uganda. The intervention components included community dialogues and empowering community health workers to sensitize expectant mothers on the use of maternal health services, and health facility strengthening. The primary outcomes were early initiation of antenatal care and completion of at least 4 ANC visits. We used Difference in Differences (DiD) analysis and multivariate regression to assess the effect of the intervention on ANC attendance.

Results: Early initiation of antenatal care increased from $35.7 \%$ to $48.1 \%$ in the intervention area and $26.9 \%$ to $40.7 \%$ in the control area but with a non-significant net change of $-1.3 \%$ (DID, $p=0.733$ ) in the intervention area with respect to changes in the control area. The DiD results revealed the intervention resulted in a 5.5\% net significant improvement in attendance of at least 4 ANC visits $(p=0.037)$. Higher education level of husband (PR1.19,95\%Cl 1.02-1.39), higher household size (PR=0.81, 95\% Cl 0.70-0.95), and higher wealth index (PR1.19,95\% Cl 1.03-1.37) predicted early initiation. Making at least 4 visits for antenatal care was influenced by post-primary education (PR1.14, 95\% $\mathrm{Cl} 1.02-1.30)$, higher wealth quintile (PR1.17, 95\% $\mathrm{Cl}$ 1.06 - 1.30), early initiation (PR1.58, 95\% $\mathrm{Cl} 1.49-1.68)$, and the community intervention (PR1.16, 95\%Cl 1.01-1.33).

Conclusion: Although the community intervention improved the attendance of at least four antenatal care visits, effect estimates are low hence raising scepticisms on the feasibility of at least 8 visits as per the new WHO recommendations. Women with less education should be prioritized in maternal and child health $(\mathrm{MCH})$ interventions as their families need economic empowerment to reduce financial barriers when access $\mathrm{MCH}$ services.

\title{
Keywords
}

\section{Community health workers, Optimal antenatal care, Early initiation, Eastern Uganda}




\section{Background}

Maternal mortality remains a significant public health issue globally. Although substantial progress has been made in reducing maternal mortality over the last two decades, the number of maternal deaths remain unacceptably high worldwide (UNICEF, 2019b). An estimated 295,000 women died in 2017 globally due to conditions related to pregnancy and childbirth, which translates to 810 maternal deaths per day (WHO, 2019). The burden of maternal mortality is disproportionately higher in low- and middle-income countries (LMICs) (94\%), with Sub-Saharan Africa accounting for two-thirds of all global maternal deaths (WHO, 2019). In Uganda, the maternal mortality ratio is estimated at 336 maternal deaths per 100,000 live births (UBOS, 2016). Most maternal deaths occur as a result of haemorrhages, sepsis, preeclampsia, unsafe abortions, and obstructed labour (WHO, 2015). A vast majority of these deaths are preventable and can be averted with access to appropriate maternal healthcare services including antenatal care (ANC) (UNICEF, 2019b).

Early and optimal ANC attendance plays a vital part in reducing perinatal and maternal mortality. In this study, early and optimal ANC attendance are defined as attending ANC at a gestational age of less than 12 weeks and for at least 4 visits, respectively as defined by the World Health Organization (WHO, 2017b). It is essential in the detection, prevention and treatment of adverse pregnancy-related outcomes (WHO, 2017b). Furthermore, it presents as an opportunity for the delivery of interventions that have been shown to positively influence maternal and child health, such as health education and counselling on pregnancy-related physiological changes and potential complications, Tetanus Toxoid (TT) administration, nutritional advice (including on supplements), blood pressure monitoring and treatment of hypertension to prevent eclampsia, provision of insecticide-treated bed nets and intermittent preventive therapy for malaria in pregnancy (IPTp), and screening and management of infections including HIV/AIDS, syphilis and other Sexually Transmitted Infections (STIS) (UNICEF, 2019a).

Until recently, the WHO recommended that pregnant women start ANC at a gestational age of less than 12 weeks and attend a total of at least four ANC visits during pregnancy (WHO, 2017b). However, WHO revised this recommendation in 2016 from four ANC contacts to eight, following recent evidence that 8 or more contacts can reduce perinatal deaths by up to 8 per 1000 births when compared to 4 visits (WHO, 2016, WHO, 2018). This recommendation will be even harder to attain, especially for women in LMICS (UNICEF, 2020). Existing literature 
indicates that only $52 \%$ of the women in Sub-Saharan Africa attended at least 4 ANC visits during pregnancy (UNICEF, 2020). Particularly, poverty, long-distance to facilities, lack of information, inadequate and poor quality services, and cultural beliefs and practices, have been cited as major barriers to optimal ANC attendance (WHO, 2019). Given these barriers, it has been suggested that community based interventions could improve uptake of services and improve maternal health (Lassi and Bhutta, 2015, Lema et al., 2014, Jacobs et al., 2018).

Community-level interventions can entail delivering interventions via different strategies such as community support groups/women groups, community mobilization, community dialogues, home visitation and training of community health workers (CHWs) (Lassi and Bhutta, 2015). Existing evidence shows that such interventions may improve breastfeeding practices and increase referrals to health facilities for pregnancy-related complications and other health care services during pregnancy, such as iron and folic acid supplementation (Lassi et al., 2016). Regarding its effect on ANC, a study conducted in Northern Uganda that included a CHW component to track women who had missed ANC appointments through Village Health Team (VHT) training, home visits, and community dialogues, resulted in significantly higher ANC attendance and skilled birth attendance (Ediau et al., 2013). Whereas community-based interventions have been shown to play a significant role in improving maternal and neonatal health (Lassi et al., 2016), existing evidence on their effect on early initiation and completion of at least four ANC visits in Eastern Uganda is limited and unclear. Therefore, this study assessed the effect of a community-level intervention on early initiation of antenatal care and completion of at least visits among women during pregnancy in Eastern Uganda.

\section{Materials and methods}

\section{Study design and study setting}

This was a quasi-experimental, non-equivalent group, pre-test-post-test design study conducted in three districts in the Busoga region (Buyende, Luuka and Iganga), located in the South-Eastern part of Uganda. These districts had very similar $\mathrm{MCH}$ indicators. A quasiexperimental design was chosen instead of a classical randomized controlled trial because it offers practical options for conducting impact evaluations in real-world settings, which is more relevant for policy development. It also effectively avoids ethical concerns associated with random assignment of individuals to treatment groups especially where one intervention is superior to the other (White and Sabarwal, 2014). Buyende and Luuka districts were the two 
intervention districts while Iganga was the control district. Busoga region has been described as the poorest region (per capita) with some of the worst health indicators in Uganda. It has a population of about 3 million people or $10 \%$ of Uganda's population, covering an area of about 7100 sq. miles (UBOS, 2016). The region has ten administrative districts - Iganga, Mayuge, Bugiri, Kamuli, Kaliro, Namutumba, Namayingo, Luuka, Buyende, and Jinja. Iganga District is also home to the Iganga/Mayuge Health Demographic Surveillance Site (HDSS), thus providing an opportunity for ongoing tracking of coverage, equity, and trends of key indicators. The HDSS area is predominantly rural but partly peri-urban in some trading areas. The three districts where the study was conducted have an estimated population of $1,100,000$ people (UBOS, 2014) and have similar rates of maternal and health services utilization indicators.

Two cross-sectional studies (one at baseline and another at the end of the intervention) were conducted. Initially, a pre-intervention cross-sectional survey was conducted in intervention and control HSDs to understand the baseline uptake of ANC, early ANC initiation, and completion of at least 4 ANC visits in the last pregnancy. Thereafter, the community-based intervention was implemented only in the intervention district for 3 years. At the end of the intervention, another cross-sectional survey was conducted in the control and intervention district and the same outcomes (as at baselines) were ascertained once more.

\section{Study population, units and eligibility criteria}

The study units were households. The study population were women, who were pregnant within 12 months prior to the surveys and were residents in the area. For inclusion, women needed to have been pregnant in the previous 12 months, regardless of whether the child was delivered preterm or full-term, and irrespective of the birth outcome (whether the baby was alive or dead). Women with severe illness at the time of the survey that would prevent them from participating and those who had not lived in the community for at least 1 year were excluded.

\section{The Intervention}

This study was part of the broader project titled "Innovations for Increasing Access to Integrated Safe Delivery, PMTCT and Newborn Care in Rural Uganda" code-named Maternal and Newborn Study (MANEST). The study was implemented in Eastern Uganda for three years (2011-2014), and the intervention comprised of using Community Health Workers (CHWs) and 
community dialogues to promote antenatal care attendance, health facility delivery, prevention of mother to child transmission (PMTCT), and family planning promotion. Other aspects including health facility strengthening. This intervention was organized as follows.

1. In the intervention districts, $3-5 \mathrm{CHWs}$ were selected in the villages by the community and were trained by the study team on how to conduct home visits and identify pregnant women. Meetings were organized in each intervention village to sensitize the community on the intended intervention. To ensure social desirability was minimized, the implementation and evaluation teams were different. Following adequate mobilization by the local village leadership with the active guidance of a Health Assistant and District Health Team member, the community in a village meeting was then asked to select a CHW who meets the job description for a $\mathrm{CHW}$. In principle, a CHW was selected if he/she met the following criteria: regular/permanent resident (resident for at least two or more years), literate (able to read and write in local language), willing to work as a volunteer, and preferably a mature female already doing some community health work. However, where the community decided to select a man, he was accepted in the project.

2. The CHWs received a five-day training conducted by the district trainers with support from national-level trainers using the Ministry of Health $(\mathrm{MoH})$ tools and guidelines. The training was conducted mainly in the local language (Lusoga) at sub-county levels with an average of 30 participants. The methods of training included: demonstrations, role plays, small group, and plenary discussions to enable skills development. A practical session in the field on how to conduct a home visit was held on the last day to facilitate knowledge translation. During the training, the $\mathrm{CHWs}$ were mentored on how to obtain informed consent during the initial home visit by the $\mathrm{CHW}$. Because $\mathrm{CHWs}$ are known, influential and respected in their communities, it was expected that using them as trusted voices would create an enabling environment and lead to better adoption or uptake of the intervention by the community. This was an important component of this approach. The CHWs sensitized the pregnant women on the importance of birth preparedness, antenatal attendance, and delivery from health facilities. The CHWs identified pregnant women and made two home visits before delivery. The CHWs also carried out community mobilization and dialogue to promote community-wide behaviour change and ownership of the intervention. Participants in intervention 
districts (Luuka and Buyende) were visited two times during pregnancy and health educated by $\mathrm{CHWs}$ and also attended community dialogues. The CHWs were supervised by health facility-based health workers and health assistants from the catchment areas. The supervisors were trained by the national $\mathrm{CHW}$ trainers together with the district trainers using adapted Ugandan $\mathrm{CHW}$ supervision guidelines. Each supervisor was assigned an average of $10 \mathrm{CHWs}$ for technical assistance in the use of counselling cards, CHW registers and report writing, and how to conduct a home visit. In the control district (Iganga),

\section{Theory of Change}

The plausibility of complex interventions such as the $\mathrm{CHW}$ program requires a convincing theory of change. This theory should be supported by a well-described hypothesis of pathways from the intervention to the outcomes (Van Belle et al., 2010). The theory of change adopted for this study has been described previously (Lema et al., 2014). Briefly, in this intervention, we expected that the home visits made by CHWs in addition to community dialogues would increase uptake of ANC especially regarding early initiation and completion of at least four ANC visits at the healthcare facility. This would be achieved through (i) counselling, which raises awareness of ANC and can provide a source of motivation as previously demonstrated (Tough et al., 2006); (ii) informing pregnant women of the location of the nearest healthcare facility that provides ANC; (iii) the visit itself serving as a reminder or "nudge" to women who were already planning to attend ANC or deliver at a healthcare facility; and (iv) CHWs exerting a normative social influence on women through their visits and by emphasizing the importance of ANC and other maternal health services. We hypothesized that these activities would lead to an improvement in the timeliness and frequency of ANC uptake as compared with standard care.

\section{Sample size and sampling procedures}

A baseline sample size of 1,582 postpartum women were interviewed in the intervention area, and 388 women from the control areas. A similar sample size of 1,661 and 401 mothers were interviewed from intervention areas and the control areas respectively during the endline evaluation. Regarding the sampling, 16 sub-counties were randomly selected (6 in each of the two intervention districts and 4 in the control district) by writing names of all sub-counties on 
small pieces of paper, then one paper was picked at a time without replacement until all subcounties were obtained. Within each sub-county, one parish was randomly selected and from each selected parish, two villages were randomly selected using the same approach used for selecting sub-counties. A list of all mothers who had given birth within 12 months of the baseline survey were listed with support from local leaders. The respondents were sampled at the village level using simple random sampling from the village listing made with the aid of the local council 1 (village) leader. From the selected/sampled village, at least 50 households were visited by the enumerators from which one eligible respondent was selected per eligible household. The same villages were considered in the endline evaluation in 2015 and a similar approach was used to select a cross-sectional sample of mothers who had given birth in the year 2014 at the endline survey.

\section{Data collection procedures}

The CHWs and the village local council (LC) leaders of the village were informed of the visit to their villages prior to the exercise. One CHW together with the LC representative guided the Research Assistants (RAs) to households that had been selected. Data were collected from the mothers in selected households through face to face interviews using a semi-structured questionnaire, developed based on reviewed literature on antenatal care attendance and community-based approaches (Finlayson and Downe, 2013, Abosse et al., 2010, Ebeigbe and Igberase, 2010, Simkhada et al., 2008). The same questionnaire was used for both baseline study and 3 years later (endline evaluation study). Since the baseline and endline were independent cross-sectional surveys, participants in the post-intervention survey are largely different from those in the baseline survey. Data were collected on sociodemographic characteristics (age, parity, household size highest education level, wealth index, occupation, and marital status) and maternal and child health service utilisation (ANC attendance and health facility deliveries). The questionnaires were filled in by experienced research assistants (RAs), who were well trained in objective interviewing to minimize recall bias from the mothers. After interviewing respondents, each RA compiled their completed questionnaires and handed them over to supervisors who reviewed the tools, checked for errors, and did the compilation. 
The key outcome variables included:

- Early ANC initiation was defined as making first contact (first visit) with a health worker within the first trimester ( $\leq 12$ weeks / or $\leq 3$ months) of pregnancy. This was selfreported and verified by checking the ANC attendance card. Having the first visit within 12 weeks of conception was coded " 1 " and otherwise coded " 0 ".

- Attending ANC at least four times during pregnancy as recommended by the WHO. Having four or more ANC visits was coded " 1 " and otherwise coded " 0 ".

The independent variables included.

- Sociodemographic and individual characteristics of women such as the age of the mother, gender, marital status, educational level of women and husbands, parity, and occupation were taken as covariates in this evaluation study. The level of education was recorded as no education, primary, or post-primary. Marital status was collapsed into married/living with a partner, and not married. Occupation was classified as "peasant farmer", "housewife", "business and other occupation" while parity was categorized into "primiparous" or " $2-4$ ", or "5 and more".

- Intervention (CHW home visits and community dialogue): This was a group variable and mothers were considered to have received the intervention if they belonged to the intervention district.

- Wealth quintiles (measured using a wealth asset index): The wealth quintiles were generated using principal components analysis (PCA) based on the information collected on assets and household structure using the Uganda Bureau of Statistics (UBOS) criteria (UBOS, 2016).

\section{Data management and quality control}

Research assistants were trained before the baseline and endline surveys. The questionnaire and consent forms were available both in English and the local language (Lusoga), with Lusoga, being the primary language used in data collection. Tools were pre-tested in 5 villages of Namungalwe sub-county (Bufuutula A, Bufuutula B, Namuusala, Nawansega A and Nawansega B) in order to fine-tune the questionnaires to suit the required objectives set for evaluation. These villages were very similar to study area settings but were not included in the final data collection. Questionnaires containing information from every participant in the study were kept securely and only accessible to the study team. Data entry was done by independent 
experienced data entry clerks who had received 2 days of training. All files were stored on password-protected computers.

\section{Statistical analysis}

The data were entered into Epi info 7 and transferred for analysis into Stata 16.0 (StataCorp, College Station, Texas, USA). Continuous variables such as age were summarized as mean and standard deviation and compared between baseline and endline using two-sample t-tests since they were normally distributed. Categorical data, on the other hand, were expressed as frequencies and proportions and compared between baseline and endline using Pearson's chisquared tests. The imperative control is made between women from the intervention area and control area; and also, to measure the net changes from baseline to endline. The women were the unit of analysis. Modified Poisson regression incorporating the difference in differences (DiD) analyses (Equation (1)) was used to understand the contribution of the intervention package towards the early initiation of ANC and completion of at least four ANC visits.

$$
\begin{gathered}
y_{i s}=\alpha+\beta_{1} \text { treatment }+\beta_{2} \text { time }+\beta_{3}(\text { treatment\#time })+\lambda_{i} \\
\sum_{i=1}^{n} x_{i t}+\mu_{i t}
\end{gathered}
$$

The treatment (intervention) and time variables were dummy variables: 1 , treatment group; 0 , non-treatment group; and 0 , before intervention; 1 , after the intervention, respectively. Yis represents the study outcomes: early initiation of ANC, and ANC attendance of 4 or more visits. $\beta 3$ is the DiD estimator indicating whether the expected mean change in outcomes before the intervention and after the intervention was different in the intervention and control groups. xit represents categorical covariates such as age, education, and occupation, while $\lambda i$ represented the covariates' estimators. Separate models were run for each study outcome. Multivariable modified Poisson regression was performed to understand the predictors of key study outcomes (early ANC initiation, optimal ANC attendance), after adjusting for known confounders such as age, and level of education. Variables with $p$ values $\leq 0.25$ at the univariate level, known confounders, and those variables that we judged to be biologically plausible were considered for multivariate analysis. Hosmer-Lemeshow was used to test the goodness of fit of the model (Hosmer et al., 1997).

\section{Ethical considerations}


Formal approval was obtained from Makerere University School of Public Health Higher Degrees, Research and Ethics Committee (HDREC), Uganda National Council for Science and Technology (UNCST) and WHO Ethical Review Committee. Approval to conduct the study was sought from the district health teams and from the local authorities where the study was conducted. Written informed consent was obtained from participants before participating in the study. An informed consent document was read to participants (either in English or local language) by the research assistants. All research procedures were conducted as per the principles of the Declaration of Helsinki and all the activities followed standard operating procedures and codes of conduct.

\section{RESULTS}

Sociodemographic characteristics of participants of women at baseline and endline in the intervention and control areas.

In total, 4,032 women (1970 at baseline and 2,062 at endline evaluation) were included in the analysis. At baseline, the age of mothers ranged from 13 to 53 years, with an average age of $26.2(S D=6.6)$. Majority of the women were peasant farmers $(81.3 \%)$ and had primary as their highest level of education (67.3\%). Women's age, parity, and level of education had similar distributions at baseline across the intervention and control arms. About $26.9 \%$ and $35.7 \%$ of the women in the intervention and control area respectively had initiated ANC early $(p=$ 0.001). Additionally, $45.9 \%$ and $53.8 \%$ of the women in intervention and control arms had completed four ANC visits $(p=0.006)$, respectively (Table 1$)$.

At the endline, the average age of mothers was $26.8(S D=6.6)$. More than half were peasants (59.2\%) and had primary as their highest education level (62.5\%). During the endline, differences in occupation $(p<0.001)$, the timing of ANC attendance $(p=0.007)$, persisted, while the differences in the number of ANC visits were no longer statistically significant. However, the differences in the husband's level of education, which was not statistically significant at the baseline, were statistically significant at the endline differences $(p=0.027)$ (Table 1). Figure 1 shows the overall frequency of ANC visits before and after the intervention. 


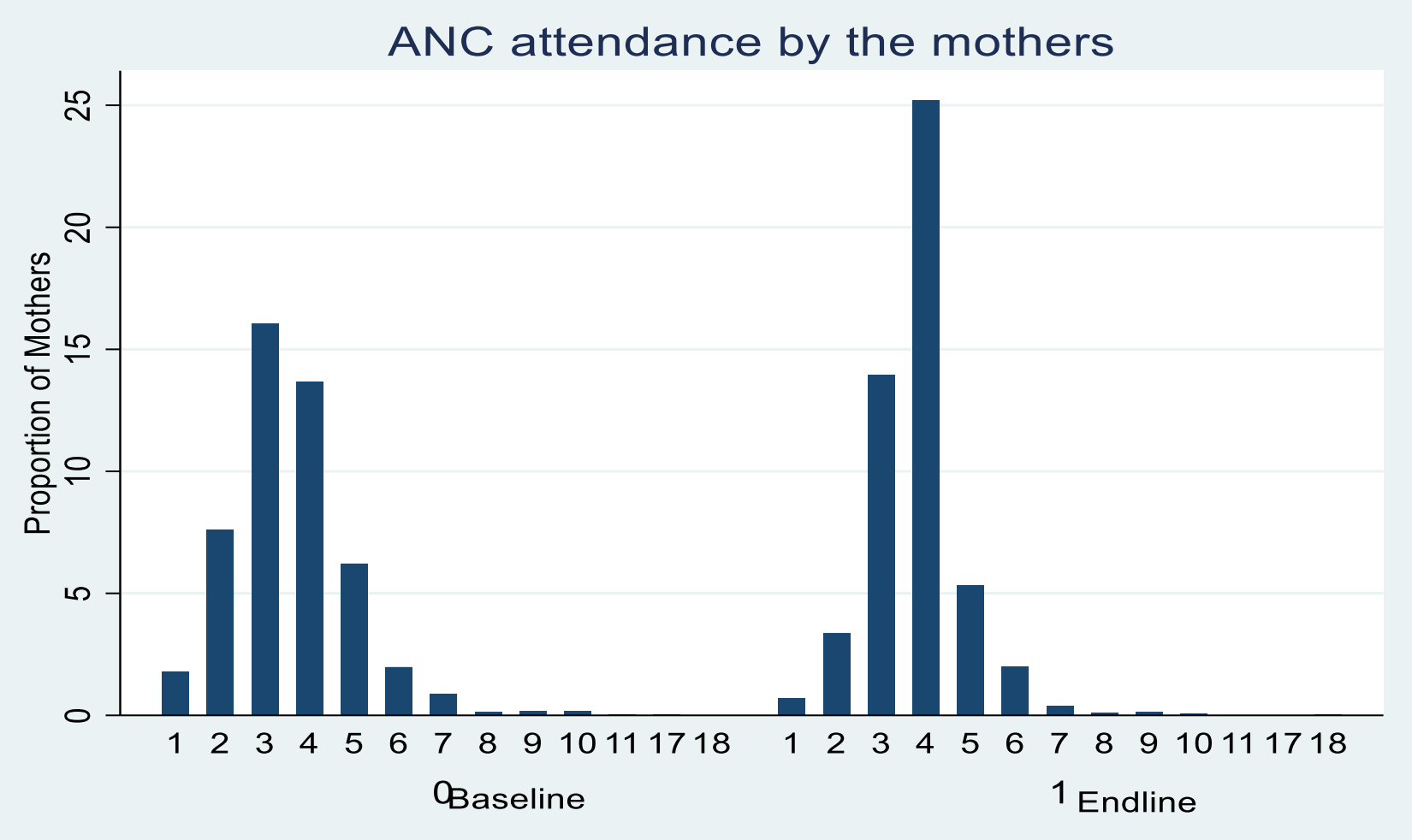

Figure 1: Number of ANC Visits before and after Community intervention

Effect of the intervention on early ANC timing and making of at least 4 ANC visits.

In the intervention area, $35.7 \%$ of the women had early ANC attendance during their last pregnancy at baseline and its uptake increased to $48.1 \%(p<0.001)$ at the endline. In the control area, $26.9 \%$ of the women presented early for ANC at baseline and this proportion increased to $40.7 \%(p<0.001)$ at the endline. The net change of $-1.3 \%$ (DID, $p=0.733$ ) in the intervention area with respect to changes in the control area was non-significant, owing to an increase of $12.4 \%$ in the intervention area and $13.8 \%$ in the control area.

Regarding ANC attendance of at least 4 times, in the intervention area, $46.2 \%$ of the women had at least four ANC visits at baseline and this significantly increased to $64.4 \%(+18.2)(p<$ 0.001 ) at endline. Likewise, in the control area, $54.1 \%$ of the women made a minimum of 4 ANC visits and this significantly increased to $66.8 \%(+12.7)(p<0.001)$. However, the net improvement ( $D I D=+5.5, p=0.037$ ) in the intervention area with respect to the control area was significant (Table 2). 
Table 1. Sociodemographic characteristics of the respondents.

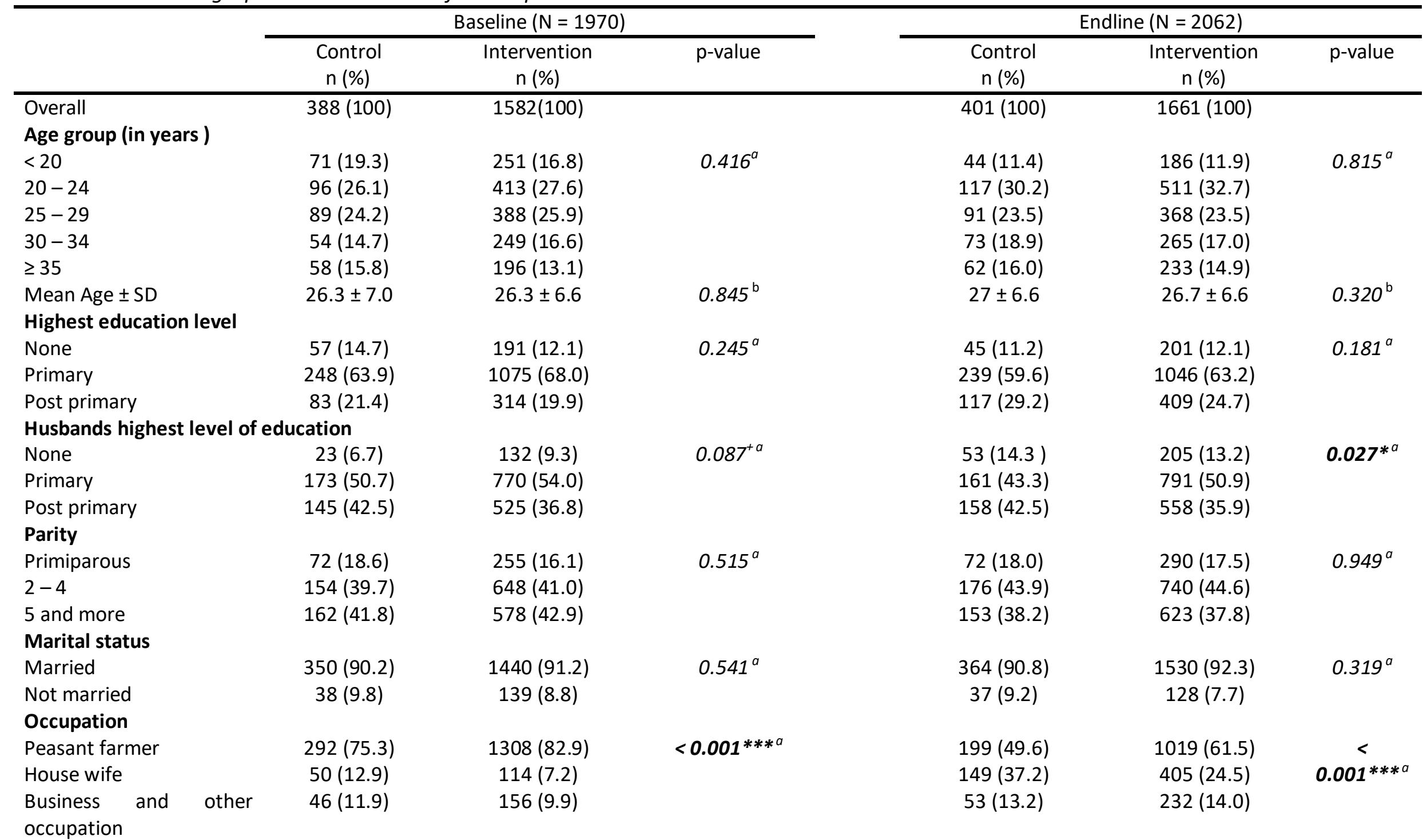

\section{Timing of first ANC visit}




\begin{tabular}{|c|c|c|c|c|c|c|}
\hline$\leq 12$ weeks & 103 (26.9) & $552(35.7)$ & $0.001 * * a$ & $161(40.7)$ & $790(48.1)$ & $0.007 * * a$ \\
\hline > 12 weeks & $280(73.1)$ & 994 (64.3) & & $235(59.3)$ & 851 (51.9) & \\
\hline \multicolumn{7}{|c|}{ Number of ANC visits } \\
\hline $1-3$ & 174 (45.9) & $828(53.8)$ & $0.006 * * a$ & $130(33.3)$ & $580(35.6)$ & $0.376^{a}$ \\
\hline $4+$ & $205(54.1)$ & $712(47.8)$ & & $261(66.7)$ & $1048(64.4)$ & \\
\hline
\end{tabular}

Note. ANC: Antenatal Care, SD: Standard Deviation, Inference ${ }^{* * *} p<0.001 ;{ }^{* *} p<0.01 ;{ }^{*} p<0.01,{ }^{+} p<0.1,{ }^{a} P$ Values based on chi squared statistics, ${ }^{\mathrm{b}} \mathrm{P}$ Values based on two sample (independent) $\mathrm{t}$ test.

Table 2. Effect of intervention on Early imitation of ANC and attendance of at least 4 ANC visits

\begin{tabular}{|c|c|c|c|c|c|c|c|c|}
\hline \multirow[t]{2}{*}{ Indicators } & \multicolumn{3}{|c|}{ Baseline $(n=1970)$} & \multicolumn{3}{|c|}{ Endline $(n=2062)$} & \multirow[t]{2}{*}{ DiD } & \multirow{2}{*}{$\begin{array}{l}\text { DID } \\
p \text { values }\end{array}$} \\
\hline & $\mathrm{C}(\%)$ & I (\%) & $\begin{array}{l}\text { Diff }(1-C)(\%) \\
\text { ( } p \text { values) }\end{array}$ & $\mathrm{C}(\%)$ & $I(\%)$ & $\begin{array}{r}\text { Diff (1-C) (\%) } \\
\text { ( } p \text { values) }\end{array}$ & & \\
\hline Early ANC initiation & 26.9 & 35.7 & $\begin{array}{c}+8.8 \\
(p=0.001)^{* *}\end{array}$ & 40.7 & 48.1 & $\begin{array}{c}+7.5 \\
(p=0.006)^{* *}\end{array}$ & -1.3 & 0.733 \\
\hline $\begin{array}{l}\text { At least } 4 \text { ANC visits } \\
\text { during pregnancy }\end{array}$ & 54.1 & 46.2 & $\begin{array}{c}-7.9 \\
(p=0.005)^{* *}\end{array}$ & 66.8 & 64.4 & $\begin{aligned}- & 2.4 \\
(p & =0.387)\end{aligned}$ & +5.5 & 0.037 \\
\hline
\end{tabular}

C: control area; I: intervention area; Diff: difference; DiD: difference in differences; ANC: Antenatal Care

*** $p<0.001 ; * * p<0.01 ;{ }^{*} p<0.01,{ }^{+} p<0.1$ 


\section{Predictors for early initiation of antenatal care.}

At the bivariable analysis, women (above 35 years) $(P R=0.8095 \% \mathrm{Cl} 0.68-0.94)$, those with higher parity $(5+)(P R=0.8195 \% \mathrm{Cl} 0.73-0.90)$, and those with household sizes above 8 (PR $=0.7395 \% \mathrm{Cl} 0.65-0.82$ ) were less likely to have early initiation of ANC compared to those young women, those with lower parities and small household sizes. On the other hand, women with post-primary education $(P R=1.3095 \% \mathrm{Cl} 1.13-1.49)$ or their husbands (PR= $1.1895 \% \mathrm{Cl} 1.03-1.36)$, those belonging to the third $(\mathrm{PR}=1.1695 \% \mathrm{Cl} 1.03-1.31)$ or fifth wealth quintile $(P R=1.2195 \% \mathrm{Cl} 1.07-1.37)$, and those in the intervention area $(P R=1.24$ $95 \% \mathrm{Cl} 1.12-1.38$ ) were more likely to present early for ANC compared to those with no formal education, belonging to lowest wealth quintile and being in the control area. (Table 3)

After adjusting for mothers' age and level of education in the multivariable modified Poisson regression analysis, the women whose husbands had post-primary education had a $19 \%$ higher likelihood of attending ANC in their first trimester compared to those whose husbands had no formal education (adjusted $\mathrm{PR}=1.19,95 \% \mathrm{Cl} 1.02-1.39$ ). Similarly, the adjusted analysis indicated that women belonging to the second (adjusted PR $=1.18,95 \% \mathrm{Cl}$ $1.04-1.35$ ), third (adjusted $P R=1.19,95 \% \mathrm{Cl} 1.04-1.36$ ), and fifth wealth quintiles (adjusted $\mathrm{PR}=1.19,95 \% \mathrm{Cl} 1.03-1.37$ ), were 18\%, 19\% and 19\% respectively more likely to attend ANC in the first trimester as compared to women in the belonging to the first wealth quintile. Women who belonged to families with a household size of at least 8 were 19\% less likely to attend ANC in their first trimester compared to those with a family size of 4 or less (adjusted PR $=0.81,95 \% \mathrm{Cl} 0.70-0.95$ ) (Table 3 ).

\section{Predictors for optimal ANC attendance (at least 4 ANC visits)}

At bivariate analysis, women aged 35 and above $(P R=0.8995 \% \mathrm{Cl} 0.80-0.99)$, and those with higher parities $(\geq 2)(P R=0.8195 \mathrm{Cl} 0.76-0.88)$ were less likely to attend a minimum of 4 ANC visits as compared to those aged below 20 years and those who were primiparous respectively. On the other hand, women who had primary education ( $P R=1695 \% \mathrm{Cl} 1.05-$ 1.28 ) or post-primary $(P R=1.3895 \% \mathrm{Cl} 1.24-1.54)$ or whose husbands had post-primary 
education ( $P R=1.2795 \mathrm{Cl} 1.14-1.42)$, or those belonging to the second $(P R=1.1695 \% \mathrm{Cl}$ $1.05-1.28)$, third $(P R=1.1795 \% \mathrm{Cl} 1.07-1.29)$, fourth $(P R=1.1195 \% \mathrm{Cl} 1.00-1.22)$ and fifth wealth quintiles $(P R=1.3395 \% \mathrm{Cl} 1.22-1.46)$ had a higher likelihood of attending at least 4 times for ANC compared to those with no education and belonging to the first quintile. Participants working as housewives $(P R=1.1895 \% \mathrm{Cl} 1.07-1.30)$ or businesswomen $(P R=1.25,95 \% \mathrm{Cl} 1.17-1.35)$, and those who presented early for ANC (PR = $1.7095 \% \mathrm{Cl} 1.62-1.79)$ were significantly more likely to attend 4 or more times for ANC compared to peasants and those who started ANC late respectively (Table 4).

After adjusting for mothers' age and education in the multivariable modified Poisson regression analysis, women who started their first ANC in their first trimester (early initiation) were at least 1.5 times more likely to attend ANC four times or more compared to those who did not start their first ANC in their first trimester (Adjusted PR $=1.58,95 \% \mathrm{Cl}$ $1.49-1.68)$. We also found that women who had post-primary education were $14 \%$ more likely to attend ANC four times or more compared to those who had no formal education (adjusted PR $=1.14,95 \% \mathrm{Cl} 1.02-1.30$ ). Women who belonged to the highest (fifth) wealth quintile were $17 \%$ more likely to attend ANC at least four times compared to those who belonged to the poorest (first) wealth quintile (adjusted PR $=1.17,95 \% \mathrm{Cl} 1.06-1.30$ ).

The estimate for the effect of the intervention (DID) shows that the intervention increased the probability of attending ANC at least 4 times by $16 \%$ (adjusted PR $=1.16,95 \% \mathrm{Cl} 1.01-$ 1.33)

(Table

4). 


\begin{tabular}{|c|c|c|c|c|c|c|}
\hline & \multicolumn{2}{|c|}{ Early ANC initiation } & \multirow{2}{*}{$\begin{array}{l}\text { Crude PR } \\
(95 \% \mathrm{Cl}) \\
\end{array}$} & \multirow[t]{2}{*}{$p$-value } & \multirow{2}{*}{$\begin{array}{l}\text { Adjusted PR } \\
(95 \% \mathrm{Cl})\end{array}$} & \multirow[t]{2}{*}{$p$-value } \\
\hline & No & Yes & & & & \\
\hline \multicolumn{7}{|l|}{ Age group (in years ) } \\
\hline$<20$ & $331(60.6)$ & $215(39.4)$ & 1 & & 1 & \\
\hline $20-24$ & $603(53.8)$ & $518(46.2)$ & $1.17(1.04-1.32)$ & $0.010 *$ & $1.15(0.99-1.34)$ & 0.061 \\
\hline $25-29$ & $543(59.1)$ & $376(40.9)$ & $1.04(0.91-1.18)$ & 0.563 & $1.02(0.86-1.22)$ & 0.776 \\
\hline $30-34$ & $385(60.8)$ & $248(39.2)$ & $0.99(0.86-1.15)$ & 0.944 & $1.02(0.83-1.25)$ & 0.828 \\
\hline$\geq 35$ & $369(68.6)$ & $169(31.4)$ & $0.80(0.68-0.94)$ & $0.006 * *$ & $0.88(0.70-1.11)$ & 0.270 \\
\hline \multicolumn{7}{|l|}{ Highest education level } \\
\hline None & $309(64.5)$ & $170(35.5)$ & 1 & & 1 & \\
\hline Primary & $1555(60.4)$ & 1016 (39.5) & $1.11(0.98-1.27)$ & 0.105 & $1.02(0.88-1.19)$ & 0.778 \\
\hline Post primary & $491(54.0)$ & $418(46.0)$ & $1.30(1.13-1.49)$ & $<0.001 * * *$ & $1.08(0.91-1.28]$ & 0.376 \\
\hline \multicolumn{7}{|c|}{ Husbands highest level of education } \\
\hline None & $250(61.7)$ & $155(38.3)$ & 1 & & 1 & \\
\hline Primary & 1154 (61.9) & $711(38.1)$ & $1.00(0.87-1.14)$ & 0.956 & $1.05(0.90-1.22)$ & 0.533 \\
\hline Post primary & $748(54.6)$ & $622(45.4)$ & $1.18(1.03-1.36)$ & $0.014 *$ & $1.19(1.02-1.39)$ & $0.025 *$ \\
\hline \multicolumn{7}{|l|}{ Parity } \\
\hline Primiparous & $380(56.0)$ & $299(44.0)$ & 1 & & 1 & \\
\hline $2-4$ & $952(56.3)$ & $739(43.7)$ & $0.99(0.89-1.10)$ & 0.882 & $0.97(0.85-1.11)$ & 0.678 \\
\hline 5 and more & $1020(64.3)$ & $567(35.7)$ & $0.81[0.73-0.90]$ & $<0.001 * * *$ & $0.98(0.82-1.17)$ & 0.817 \\
\hline \multicolumn{7}{|l|}{ Marital status } \\
\hline Married & $2151(59.3)$ & 1477 (40.7) & 1 & & & \\
\hline Not married & $205(61.8)$ & $127(38.3)$ & $0.94(0.82-1.08)$ & 0.391 & & \\
\hline \multicolumn{7}{|l|}{ Occupation } \\
\hline Peasant farmer & $1708(61.7)$ & 1060 (38.3) & 1 & & 1 & \\
\hline House wife & $388(54.8)$ & $320(45.2)$ & $1.18(1.07-1.30)$ & $0.001 * *$ & $0.99(0.89-1.10)$ & 0.877 \\
\hline Business and other occupation ${ }^{\S}$ & $258(53.6)$ & $223(46.4)$ & $1.21(1.09-1.35)$ & $<0.001 * * *$ & $1.03(0.91-1.18)$ & 0.625 \\
\hline \multicolumn{7}{|l|}{ Household size } \\
\hline $1-4$ & $682(54.4)$ & $572(45.6)$ & 1 & & 1 & \\
\hline $5-8$ & $1136(59.8)$ & $763(40.2)$ & $0.88(0.82-0.96)$ & $0.002 * *$ & $0.94(0.89-1.10)$ & 0.218 \\
\hline
\end{tabular}




\begin{tabular}{|c|c|c|c|c|c|c|}
\hline$\geq 8$ & $537(66.5)$ & $270(33.5)$ & $0.73(0.65-0.82)$ & $<0.001 * *$ & $0.81(0.70-0.95)$ & $0.010^{*}$ \\
\hline \multicolumn{7}{|l|}{ Wealth index } \\
\hline Lowest & $469(63.0)$ & $275(37.0)$ & 1 & & 1 & \\
\hline Second & $456(58.8)$ & $319(41.2)$ & $1.11(0.98-1.26)$ & 0.094 & $1.18(1.04-1.35)$ & $0.013^{*}$ \\
\hline Middle & $445(57.2)$ & $333(42.8)$ & $1.16(1.03-1.31)$ & $0.021 *$ & $1.19(1.04-1.36)$ & $0.011^{*}$ \\
\hline Fourth & $452(63.1)$ & $264(36.9)$ & $1.00(0.87-1.14)$ & 0.971 & $1.04(0.90-1.20)$ & 0.641 \\
\hline Highest & $404(55.2)$ & $328(44.8)$ & $1.21(1.07-1.37)$ & $0.002^{*}$ & $1.19(1.03-1.37)$ & $0.020^{*}$ \\
\hline \multicolumn{7}{|l|}{ Time period } \\
\hline Baseline & $1274(66.0)$ & $655(34.0)$ & 1 & & 1 & \\
\hline Endline & $1086(53.3)$ & $951(46.7)$ & $1.37(1.27-1.49)$ & $<0.001 * * *$ & $1.63(1.29-2.07)$ & $<0.001 * * *$ \\
\hline \multicolumn{7}{|l|}{ Received Intervention } \\
\hline No & $515(66.1)$ & 264 (33.9) & 1 & & 1 & \\
\hline Yes & 1845 (57.9) & $1342(42.1)$ & $1.24(1.12-1.38)$ & $<0.001 * * *$ & $1.41(1.15-1.74)$ & 0.001 \\
\hline Time period* intervention & & & & & $0.84(0.66-1.09)$ & 0.196 \\
\hline
\end{tabular}

Note. $\mathrm{Cl}$ : confidence interval; PR = Prevalence ratio; Inference ${ }^{* * *} p<0.001 ;{ }^{* *} p<0.01 ;{ }^{*} p<0.01,{ }^{+} p<0.1$ 
Table 4: Predictors of optimal ANC attendance (4+Visits) using modified Poisson regression

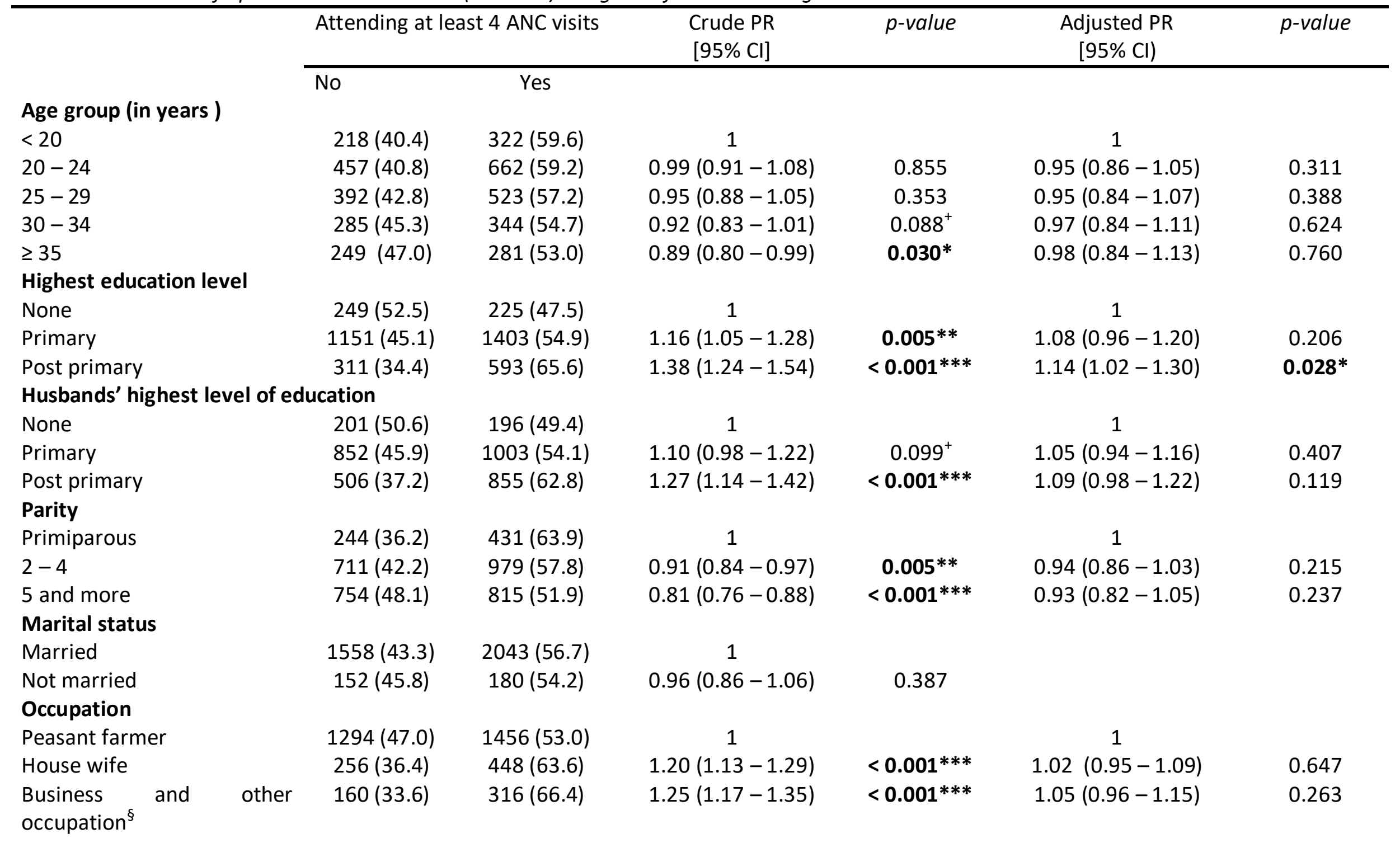




\begin{tabular}{|c|c|c|c|c|c|c|}
\hline \multicolumn{7}{|l|}{ Household size } \\
\hline $1-4$ & $479(38.4)$ & $767(61.6)$ & 1 & & 1 & \\
\hline $5-8$ & $838(44.4)$ & $1049(55.7)$ & $0.90(0.85-0.96)$ & $0.001 * *$ & $0.99(0.91-1.06)$ & 0.676 \\
\hline$\geq 8$ & $393(49.1)$ & $407(50.9)$ & $0.83(0.76-0.90)$ & $<0.001 * * *$ & $0.96([0.86-1.06)$ & 0.376 \\
\hline \multicolumn{7}{|l|}{ Wealth index } \\
\hline Lowest & $379(50.8)$ & $367(49.2)$ & 1 & & 1 & \\
\hline Second & $326(42.7)$ & $437(57.3)$ & $1.16(1.05-1.28)$ & $0.002 * *$ & $1.09(0.99-1.20)$ & $0.068^{+}$ \\
\hline Middle & $328(42.3)$ & $447(57.7)$ & $1.17(1.07-1.29)$ & $0.001 * *$ & $1.09(0.99-1.20)$ & $0.078^{+}$ \\
\hline Fourth & $323(45.6)$ & $385(54.4)$ & $1.11(1.00-1.22)$ & $0.048 *$ & $1.04(0.94-1.16)$ & 0.400 \\
\hline Highest & $250(34.5)$ & $474(65.5)$ & $1.33(1.22-1.46)$ & $<0.001 * *$ & $1.17(1.06-1.30)$ & $0.001 * *$ \\
\hline \multicolumn{7}{|l|}{ Early ANC initiation } \\
\hline No (> 12 weeks) & $1308(55.9)$ & $1034(44.2)$ & 1 & & 1 & \\
\hline Yes ( $\leq 12$ weeks) & 393 (24.9) & $1185(75.1)$ & $1.70(1.62-1.79)$ & $<0.001 * * *$ & $1.58(1.49-1.68)$ & $<0.001 * * *$ \\
\hline \multicolumn{7}{|l|}{ Time period } \\
\hline Baseline & $1002(52.2)$ & $917(47.8)$ & 1 & & 1 & \\
\hline Endline & $710(35.2)$ & $1309(64.8)$ & $1.36(1.28-1.44)$ & $<0.001 * * *$ & $1.13(1.00-1.27)$ & $0.055^{+}$ \\
\hline \multicolumn{7}{|l|}{ Received Intervention } \\
\hline No & $304(39.5)$ & $466(60.5)$ & 1 & & 1 & \\
\hline Yes & $1408(44.4)$ & $1760(55.6)$ & $0.92(0.86-0.98)$ & $0.010 *$ & $0.82(0.73-0.92)$ & $0.001 * *$ \\
\hline Time* intervention (DiD) & & & & & $1.16(1.01-1.33)$ & $0.036 *$ \\
\hline
\end{tabular}

Note. $\mathrm{Cl}$ : confidence interval; PR = Prevalence ratio; Inference ${ }^{* * *} \mathrm{p}<0.001 ;{ }^{* *} \mathrm{p}<0.01 ;{ }^{*} \mathrm{p}<0.01,{ }^{+} \mathrm{p}<0.1$ 


\section{Discussion}

This study sought to assess the effect of community-level interventions on early and optimal (at least 4 visits) ANC attendance. The findings have indicated that community intervention can lead to improvement in the uptake of maternal and child health services. The approach led to increased fourth ANC attendance which implies it potentially improves access to $\mathrm{MCH}$ services hence mitigating the risk of maternal and child mortality. However, improving ANC attendance, attaining 4 visits is still lower than national guidelines which raise concerns on whether the current WHO call for at least 8 ANC visits during pregnancy is feasible. Early ANC initiation was influenced by the husband's education level, household size, and wealth index. Higher education level, higher wealth quintile, early ANC initiation and Community intervention were associated with optimal ANC attendance. Addressing socioeconomic disparities in addition to the community intervention may have significant effect on ANC attendance.

There was an overall increase in early ANC initiation rates and completion of at least 4 ANC visits in both intervention and control arms although estimates remain lower than recommended in the WHO guidelines. The general improvement in ANC attendance including early ANC initiation equally across both the intervention and control arms may be explained at least in part by the health facility strengthening which impacted both trial arms, but could also by the secular trend towards improved maternal and Newborn care. CHWs are active in all districts regardless of the intervention and they are trained to identify and visit pregnant women; health educate and refer them for hospital care including ANC. The CHW strategy was nationally popularised and Maternal and Perinatal Death Review Strategy established was established in all districts (Benova et al., 2018). Moreover, a similar intervention had been implemented in the control area (Iganga) just one year before this study which may partly explain the non-significant effect of this intervention (Waiswa et al., 2015).

Early initiation of antenatal care allows early detection of complications and their appropriate management (Carroli et al., 2001). In our study, early ANC initiation was predicted by parity, wealth index, husband's education level, and CHW intervention in the intervention area. Early initiation of ANC and optimal ANC attendance were significantly associated with receiving the 
community intervention. CHWs' efforts such as sensitization of mothers on the importance of timely uptake of ANC and at least 4 ANC visits through routine home visits could have convinced mothers to attend ANC early. Similarly, recent intervention studies showed that trained and supervised CHWs were able to successfully identify and visit pregnant women at home in order to promote various healthy practices, including early and optimal ANC attendance (Waiswa et al., 2015, Ekirapa-Kiracho et al., 2017). A similar study in India demonstrated that CHWs can encourage mothers to consider early initiation of ANC and retention in the maternity care continuum (Agarwal et al., 2019). Therefore, CHW interventions are important in the promotion of maternal health hence provides important implications for policy and practice in Uganda and other similar settings where CHW programmes for maternal and Newborn care are being designed or scaled up.

Our findings showed that wealth status had a significant impact on early ANC initiation. Compared with the women in the poorest wealth quintile, those in the higher quintile were more likely to attend ANC in the first trimester. Our results are consistent with past findings, for instance, cross-sectional studies conducted in Nepal, Ghana, and Nigeria showed that ANC attendance increased with an increase in wealth status (Kuuire et al., 2017, Manyeh et al., 2020, Paudel et al., 2017). This is because women from a higher wealth index can afford the costs incurred in accessing maternal healthcare such as transportation charges to and from the healthcare facility and costs related to health services compared to their counterparts. Indeed, previous studies have revealed that the cost of health services is an important determinant for late ANC attendance, and is therefore likely to act as a barrier to timely initiation of ANC among women from poorer households (Venyuy et al., 2020). Therefore, with a high proportion of mothers living below the poverty line in the Busoga region, interventions targeted at economic empowerment of women and their families such as savings, transport vouchers and community insurance programs could increase early initiation of ANC.

Our study revealed that women whose husbands had post-primary education were $19 \%$ more likely to attend ANC in their first trimester compared to those whose husbands had no formal education. Similarly, previous studies indicated that paternal level of education was a statistically significant predictor for early ANC initiation (Turyasiima et al., 2014, Wolde et al., 
2018). This could be because the increase in education level among husbands is likely to increase their knowledge of issues pertaining to maternal healthcare including ANC attendance and also increase economic access to these services. This could, therefore, lead to their influence and support of the women for early ANC initiation. In addition, the literature indicates that men being heads of families and the main decision-makers play huge roles in the influence and support of women's health-seeking decisions and behaviours (Sakeah et al., 2017). Therefore, men's education level is vital in improving maternal and neonatal health decision making.

Women who belonged to families with a household size of at least 8 were $19 \%$ less likely to attend ANC in their first trimester compared to those with a family size of 4 or less. These findings are in agreement with those in a cross-sectional study conducted in Nigeria where large household size was significantly associated with delayed ANC attendance (Kuuire et al., 2017, Abosse et al., 2010). This could be because large household sizes, especially in rural areas, often face financial barriers in relation to access to health services. In addition, multiparous women might not consider delayed initiation of ANC as a problem owing to experience from their previous pregnancies. This study, therefore, demonstrates the importance of emphasizing family planning and child spacing among families in order to improve maternal health-seeking behaviours. Women with already large families need continuous sensitizations such as through outreach sessions to encourage ANC attendance.

Early initiation for ANC was a major predictor for attendance of 4 or more ANC visits. In our study, women who started their first ANC in the first trimester were 1.5 times more likely to attend ANC at least four times compared to those who did not start their first ANC in the first trimester. Previous studies on the determinants of ANC visits showed that mothers' late initiation of ANC was negatively associated with attendance of 4 or more ANC visits (Atuhaire and Mugisha, 2020, Ekirapa-Kiracho et al., 2017). Early initiation of ANC is a critical opportunity for the delivery of healthcare, health education, and vital information on the status of their pregnancy (WHO, 2017a), which in turn informs continuous ANC attendance throughout pregnancy. This finding implies that timely initiation of ANC during pregnancy consequently 
leads to optimal ANC attendance. Strategies that promote early ANC attendance such as community mobilization, $\mathrm{CHW}$ involvement and home visits should be emphasized.

Findings from this study also indicated that women who had post-primary education were $14 \%$ more likely to attend ANC four times or more compared to those with no formal education. These findings corroborate those in studies conducted in Nigeria and Tanzania where higher maternal education was significantly associated with optimal attendance of ANC (Dahiru and Oche, 2015, Gupta et al., 2014). This could be because higher education attainment among women often comes with financial independence, employment, and awareness of the benefits of health services, hence improved access to maternal health services. Moreover, women with higher education are more likely to realise the benefits of using maternal healthcare services (Matsumura and Gubhaju, 2001). Education not only increases women's confidence but also their autonomous decision-making power within the household (Matsumura and Gubhaju, 2001). Therefore, educated women are more likely to make better and informed health-related decisions. More sensitization of the benefits of ANC is therefore needed especially for women with low education status.

Women who belonged to the highest (fifth) wealth quintile were $17 \%$ more likely to attend ANC at least four times compared to those who belonged to the poorest (first) wealth quintile. A higher income level ensures economic and physical access to maternal healthcare services, hence women belonging to the highest wealth quintile are more likely to attend ANC optimally. Cost of accessing care (travel cost, service fees, equipment cost) is an important determinant of whether to seek $\mathrm{MCH}$ services or not, especially where distances to healthcare facilities are large such as in these rural settings (Mugambe et al., 2021, Hitimana et al., 2018). Consequently, women belonging to lower wealth quintiles are less likely to attend ANC frequently hence less likely to reach recommended optimal guidelines. Our findings confirm with those in previous studies that found that low incomes or wealth indices were associated with predicted low ANC utilization rates. (Dahiru and Oche, 2015, Fagbamigbe and Idemudia, 2017). As previously highlighted, interventions targeted at the economic empowerment of women and their families could increase the frequency of ANC attendance. 


\section{Strengths and limitations of the study}

The study involved a large sample size and several districts hence the results may be generalized to the eastern region of Uganda and other similar settings. Despite the above strengths, the study was not without limitations hence findings should be interpreted with caution. Some of this study's findings may have been affected by recall bias because some respondents had taken almost a year since they gave birth and may not accurately recall all pregnancy events. However, the authors' assumption and belief are that events surrounding pregnancy and childbirth are key events and that mothers are often able to remember them. Secondly, a similar intervention had been implemented in the control area (Iganga) just one year before this study started which may partly explain the non-significant effect of the $\mathrm{CHW}$ intervention. Thirdly, the study outcomes were assessed only through self-report which could have introduced social desirability bias. However, this was minimized by explaining the relevance of study findings and assuring participants of privacy and confidentiality of their responses. Lastly, the use of a quasi-experimental design has its inherent limitations. For example, it may not have taken care of confounders that are often best handled through randomization. In addition, such studies may need to be complemented with qualitative research for some explanations of observed trends.

\section{Conclusions}

The community intervention significantly improved the uptake of at least four ANC visits in the intervention group over the control group. The improvement in ANC uptake was still lower than Ministry of Health guidelines which raises concerns on the feasibility of attaining the 8 ANC visits currently recommended by WHO. However, early ANC initiation was influenced by women's parity, wealth index and husband's education level. Attendance of at least 4 visits was associated with women's education level, wealth index, and community intervention. There is a need to strengthen CHW programmes, and prioritize less educated women with more awareness programmes, and promote economic empowerment programmes to enhance uptake of the essential $\mathrm{MCH}$ services.

\section{ABBREVIATIONS}


ANC: Antenatal Care

CHW: Community Health Workers

DID: Difference in Differences

MCH: Maternal and Child Health

MOH: Ministry of Health, Uganda

PR: Prevalence ratio

UBOS: Uganda Bureau of Statistics

WHO: World Health Organization

\section{Ethics approval and consent to participate}

Ethical clearance was obtained from the Makerere University School of Public Health Higher Degrees and Research Ethics Committee (HDREC) and the WHO Ethical Review Committee. Permission was also obtained from the district authorities of the study areas. Written informed consent was obtained from all participants and confidentially was highly observed. All methods were carried out in accordance with relevant guidelines and regulations.

\section{Consent for publication}

Not applicable.

\section{Availability of data and materials}

The datasets used during the current study are available from the corresponding author on reasonable request

\section{Competing interests}

The authors declare that they have no competing interests

\section{Funding}


This study was funded by World Health Organization (WHO) and Department for International Development (DFID). The funders had no role in study design, data collection and analysis, decision to publish, or preparation of the manuscript.

\section{Authors' contributions}

PW, EKE, and STW conceived and designed the study. BK, GN, KM, SN and PW supported in the with implementation, monitoring and evaluation of the project. STW, AN and TS analysed the data. STW, AN, RMK, DM, PW and FW reviewed the analysis and wrote the first draft of the manuscript. RKM, JBI, EKE, DM, FW, GN, SN, PW critically reviewed the manuscript for intellectual content. All authors have read and approved the final version of the manuscript. PW acquired funding for the study.

\section{Acknowledgments}

We would like to thank the study participants for sparing their time to respond to the data collection tools. We also thank the district and local area authorities for their cooperation and support during data collection. Special thanks also go to the research assistants for their invaluable effort in collecting the data.

\section{REFERENCES}

ABOSSE, Z., WOLDIE, M. \& OLOLO, S. 2010. Factors influencing antenatal care service utilization in hadiya zone. Ethiop J Health Sci, 20, 75-82.

AGARWAL, S., CURTIS, S., ANGELES, G., SPEIZER, I., SINGH, K. \& THOMAS, J. 2019. Are community health workers effective in retaining women in the maternity care continuum? Evidence from India. BMJ Global Health, 4, e001557.

ATUHAIRE, S. \& MUGISHA, J. 2020. Determinants of antenatal care visits and their impact on the choice of birthplace among mothers in Uganda: a systematic review. Obstet Gynecol Int J, 11, 77-81.

BENOVA, L., DENNIS, M. L., LANGE, I. L., CAMPBELL, O. M. R., WAISWA, P., HAEMMERLI, M., FERNANDEZ, Y., KERBER, K., LAWN, J. E., SANTOS, A. C., MATOVU, F., MACLEOD, D., GOODMAN, C., PENN-KEKANA, L., SSENGOOBA, F. \& LYNCH, C. A. 2018. Two decades of antenatal and delivery care in Uganda: a cross-sectional study using Demographic and Health Surveys. BMC Health Services Research, 18, 758.

CARROLI, G., ROONEY, C. \& VILLAR, J. 2001. How effective is antenatal care in preventing maternal mortality and serious morbidity? An overview of the evidence. Paediatric and perinatal Epidemiology, 15, 1-42.

DAHIRU, T. \& OCHE, O. M. 2015. Determinants of antenatal care, institutional delivery and postnatal care services utilization in Nigeria. Pan African medical journal, 21. 
EBEIGBE, P. N. \& IGBERASE, G. O. 2010. Reasons given by pregnant women for late initiation of antenatal care in the niger delta, Nigeria. Ghana medical journal, 44, 47-51.

EDIAU, M., WANYENZE, R. K., MACHINGAIDZE, S., OTIM, G., OLWEDO, A., IRISO, R. \& TUMWESIGYE, N. M. 2013. Trends in antenatal care attendance and health facility delivery following community and health facility systems strengthening interventions in Northern Uganda. BMC Pregnancy and Childbirth, 13, 189.

EKIRAPA-KIRACHO, E., MUHUMUZA KANANURA, R., TETUI, M., NAMAZZI, G., MUTEBI, A., GEORGE, A., PAINA, L., WAISWA, P., BUMBA, A., MULEKWA, G., NAKIGANDA-BUSIKU, D., LYAGOBA, M., NAIGA, H., PUTAN, M., KULWENZA, A., AJEANI, J., KAKAIRE-KIRUNDA, A., MAKUMBI, F., ATUYAMBE, L., OKUI, O. \& NAMUSOKE KIWANUKA, S. 2017. Effect of a participatory multisectoral maternal and newborn intervention on maternal health service utilization and newborn care practices: a quasi-experimental study in three rural Ugandan districts. Glob Health Action, 10, 1363506.

FAGBAMIGBE, A. F. \& IDEMUDIA, E. S. 2017. Wealth and antenatal care utilization in Nigeria: policy implications. Health care for women international, 38, 17-37.

FINLAYSON, K. \& DOWNE, S. 2013. Why do women not use antenatal services in low- and middleincome countries? A meta-synthesis of qualitative studies. PLoS medicine, 10, e1001373e1001373.

GUPTA, S., YAMADA, G., MPEMBENI, R., FRUMENCE, G., CALLAGHAN-KORU, J. A., STEVENSON, R., BRANDES, N. \& BAQUI, A. H. 2014. Factors associated with four or more antenatal care visits and its decline among pregnant women in Tanzania between 1999 and 2010. PloS one, 9, e101893e101893.

HITIMANA, R., LINDHOLM, L., KRANTZ, G., NZAYIRAMBAHO, M. \& PULKKI-BRÄNNSTRÖM, A.-M. 2018. Cost of antenatal care for the health sector and for households in Rwanda. BMC Health Services Research, 18, 262.

HOSMER, D. W., HOSMER, T., LE CESSIE, S. \& LEMESHOW, S. 1997. A comparison of goodness-of-fit tests for the logistic regression model. Statistics in medicine, 16, 965-980.

JACOBS, C., MICHELO, C., CHOLA, M., OLIPHANT, N., HALWIINDI, H., MASWENYEHO, S., BABOO, K. S. \& MOSHABELA, M. 2018. Evaluation of a community-based intervention to improve maternal and neonatal health service coverage in the most rural and remote districts of Zambia. PloS one, 13, e0190145.

KUUIRE, V. Z., KANGMENNAANG, J., ATUOYE, K. N., ANTABE, R., BOAMAH, S. A., VERCILLO, S., AMOYAW, J. A. \& LUGINAAH, I. 2017. Timing and utilisation of antenatal care service in Nigeria and Malawi. Global Public Health, 12, 711-727.

LASSI, Z., KUMAR, R. \& BHUTTA, Z. 2016. Chapter 14: Community-based care to improve maternal, newborn, and child health. Reproducfive, maternal, newborn, and child health: Disease control priorifies, The International Bank for Reconstruction and Development/The World Bank, Washington, $D C$, viewed, 5.

LASSI, Z. S. \& BHUTTA, Z. A. 2015. Community-based intervention packages for reducing maternal and neonatal morbidity and mortality and improving neonatal outcomes. Cochrane database of systematic reviews.

LEMA, I. A., SANDO, D., MAGESA, L., MACHUMI, L., MUNGURE, E., MWANYIKA SANDO, M., GELDSETZER, P., FOSTER, D., KAJOKA, D., NABURI, H., EKSTRÖM, A. M., SPIEGELMAN, D., LI, N., CHALAMILLA, G., FAWZI, W. \& BÄRNIGHAUSEN, T. 2014. Community health workers to improve antenatal care and PMTCT uptake in Dar es Salaam, Tanzania: a quantitative performance evaluation. Journal of acquired immune deficiency syndromes (1999), 67 Suppl 4, S195-S201. 
MANYEH, A. K., AMU, A., WILLIAMS, J. \& GYAPONG, M. 2020. Factors associated with the timing of antenatal clinic attendance among first-time mothers in rural southern Ghana. BMC Pregnancy and Childbirth, 20, 47.

MATSUMURA, M. \& GUBHAJU, B. 2001. Women's Status, Household Structure and the Utilization of Maternal Health Services in Nepal: Even primary-leve1 education can significantly increase the chances of a woman using maternal health care from a modem health facility. Asia-Pacific Population Journal, 16, 23-44.

MUGAMBE, R. K., YAKUBU, H., WAFULA, S. T., SSEKAMATTE, T., KASASA, S., ISUNJU, J. B., HALAGE, A. A., OSURET, J., BWIRE, C., SSEMPEBWA, J. C., WANG, Y., MCGRIFF, J. A. \& MOE, C. L. 2021. Factors associated with health facility deliveries among mothers living in hospital catchment areas in Rukungiri and Kanungu districts, Uganda. BMC Pregnancy and Childbirth, 21, 329.

PAUDEL, Y. R., JHA, T. \& MEHATA, S. 2017. Timing of first antenatal care (ANC) and inequalities in early initiation of ANC in Nepal. Frontiers in public health, 5, 242.

SAKEAH, E., OKAWA, S., REXFORD ODURO, A., SHIBANUMA, A., ANSAH, E., KIKUCHI, K., GYAPONG, M., OWUSU-AGYEI, S., WILLIAMS, J., DEBPUUR, C., YEJI, F., KUKULA, V. A., ENUAMEH, Y., ASARE, G. Q., AGYEKUM, E. O., ADDAI, S., SARPONG, D., ADJEI, K., TAWIAH, C., YASUOKA, J., NANISHI, K., JIMBA, M., HODGSON, A. \& THE GHANA, E. T. 2017. Determinants of attending antenatal care at least four times in rural Ghana: analysis of a cross-sectional survey. Global Health Action, 10, 1291879.

SIMKHADA, B., TEIJLINGEN, E. R., PORTER, M. \& SIMKHADA, P. 2008. Factors affecting the utilization of antenatal care in developing countries: systematic review of the literature. J Adv Nurs, 61, 24460.

TOUGH, S. C., JOHNSTON, D. W., SIEVER, J. E., JORGENSON, G., SLOCOMBE, L., LANE, C. \& CLARKE, M. 2006. Does supplementary prenatal nursing and home visitation support improve resource use in a universal health care system? A randomized controlled trial in Canada. Birth, 33, 183-94.

TURYASIIMA, M., TUGUME, R., OPENY, A., AHAIRWOMUGISHA, E., OPIO, R., NTUNGUKA, M., MAHULO, N., AKERA, P. \& ODONGO-AGINYA, E. 2014. DETERMINANTS OF FIRST ANTENATAL CARE VISIT BY PREGNANT WOMEN AT COMMUNITY BASED EDUCATION, RESEARCH AND SERVICE SITES IN NORTHERN UGANDA. East African medical journal, 91, 317-322.

UBOS 2014. National population and housing census 2014 provisional results, Uganda Bureau of Statistics. Kampala: Ministry of planning and regional development.

UBOS. 2016. Uganda Demographic and Health Survey [Online]. Available: http://www.health.go.ug/content/uganda-demographic-and-health-survey-2016 [Accessed].

UNICEF. 2019a. Antenatal care [Online]. Available: https://data.unicef.org/topic/maternalhealth/antenatal-care/ [Accessed 25th October 2020].

UNICEF. 2019b. Maternal mortality [Online]. Available: https://data.unicef.org/topic/maternalhealth/maternal-mortality/ [Accessed 25th October 2020].

UNICEF. 2020. Antenatal care [Online]. Available: https://data.unicef.org/topic/maternalhealth/antenatal-care/ [Accessed 4th January 2020].

VAN BELLE, S. B., MARCHAL, B., DUBOURG, D. \& KEGELS, G. 2010. How to develop a theory-driven evaluation design? Lessons learned from an adolescent sexual and reproductive health programme in West Africa. BMC Public Health, 10, 741.

VENYUY, M., CUMBER, S., CLAUDE NKFUSAI, N., BEDE, F., IJANG, Y., WEPNGONG, E., BAMA, S., TSOKAGWEGWENI, J. \& TEBEU, P. M. 2020. Determinants to late antenatal clinic start among pregnant women: the case of Saint Elizabeth General Hospital, Shishong, Cameroon. Pan African Medical Journal, 35.

WAISWA, P., PARIYO, G., KALLANDER, K., AKUZE, J., NAMAZZI, G., EKIRAPA-KIRACHO, E., KERBER, K., SENGENDO, H., ALIGANYIRA, P., LAWN, J. E. \& PETERSON, S. 2015. Effect of the Uganda 
Newborn Study on care-seeking and care practices: a cluster-randomised controlled trial. Global Health Action, 8, 24584.

WHITE, H. \& SABARWAL, S. 2014. Quasi-experimental design and methods. Methodological briefs: impact evaluation.

WHO. 2015. MDG 5: improve maternal health [Online]. Available: https://www.who.int/topics/millennium_development_goals/maternal_health/en/ [Accessed 2nd November 2020].

WHO. 2016. New guidelines on antenatal care for a positive pregnancy experience [Online]. Available: https://www.who.int/news/item/07-11-2016-new-guidelines-on-antenatal-care-for-a-positivepregnancy-experience [Accessed 4th January 2020].

WHO. 2017a. More women worldwide receive early antenatal care, but great inequalities remain [Online]. Available: https://www.who.int/reproductivehealth/news/antenatal-care/en/ [Accessed 2nd November 2020].

WHO. 2017b. New guidelines on antenatal care for a positive pregnancy experience [Online]. Available: https://www.who.int/reproductivehealth/news/antenatal-care/en/ [Accessed 2nd November 2020].

WHO 2018. WHO recommendations on antenatal care for a positive pregnancy experience: summary: highlights and key messages from the World Health Organization's 2016 global recommendations for routine antenatal care. World Health Organization.

WHO. 2019. Maternal mortality [Online]. Available: https://www.who.int/news-room/factsheets/detail/maternal-mortality [Accessed 4th March 2020].

WOLDE, F., MULAW, Z., ZENA, T., BIADGO, B. \& LIMENIH, M. A. 2018. Determinants of late initiation for antenatal care follow up: the case of northern Ethiopian pregnant women. BMC Research Notes, $11,837$. 